\title{
Tyrosine-Protein Kinase Fyn
}

National Cancer Institute

\section{Source}

National Cancer Institute. Tyrosine-Protein Kinase Fyn. NCI Thesaurus. Code C17574.

Tyrosine-protein kinase Fyn (537 aa, $\sim 61 \mathrm{kDa}$ ) is encoded by the human FYN gene. This protein is involved in tyrosine phosphorylation, cytoskeleton remodeling and signal transduction 